\title{
/BIOTOOLS
}

\section{Sepsis: The More, the Murkier}

The preponderance of sepsis patents is as likely to provide riches as it is bankruptcy

\author{
PETER E. H I G H F I E L D
}

Anyone who

wishes to have a

complete picture

of research needs

to search patent

literature,

particularly

when the field

has a high

commercial

profile.

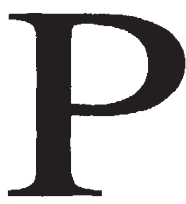

atents are a fact of life for anyone working in biotechnology. Anyone who wishes to have a complete picture of research needs to search the patent literature, particularly when the field has a high commercial profile.

Consider septic shock, for example. The potential market for septic shcok therapeutic treatments is about $\$ 500$ million per year. The number of patents issued on sepsis in 1993 was over three times that issued in 1990. The proportion of patents relating to sepsis, out of the total number of pharmaceutical patents, more than doubled between these years (from 0.14 to 0.32 percent). These figures may attest to the importance of the sepsis market. On the other hand, they may attest merely to the complexity of sepsis.

A recent review of patents in sepsis ${ }^{2}$ concludes that septic shock ". . .occurs from multiple etiologies with a complex cascade of effects that occur rapidly and dramatically. This makes it difficult to predict the patients at risk and the outcome of treatment, hence the multiplicity of approaches to therapy."

Another explanation is that the "complex cascade of effects" in sepsis permits a plethora of potential intervention points in the disease, each one of which may be (and often is) patented by a different company.

The eighteen compounds in clinical phases demonstrate the variety of approaches that are being taken. There are the famous compounds for bacterial lipopolysaccharide (LPS) neutralization-like Xoma's (Santa Monica, CA) Xomen E5 [WO8808135] and Centocor's (Malvern, PA) Centoxin [WO8501659]and the not-so-famous, such as a polyvalent anti-LPS from Univax (Rockville, MD) [WO9216230] and Eisai's (Tokyo) lipid A analog, E-5531 [EP-536969A]. Then there are the anticytokine approaches; these include tissue necrosis factor (TNF) inhibitors like the murine [WO9000902] and humanized [WO9211383] antibodies from Bayer's (Leverkusen, Germany) collaborations with Chiron (Emeryville, CA) and Celltech (Slough, U.K.); the IL-1 inhibitors such as Synergen's (Boulder, CO) Antril [WO9216221] and Immunex' (Seattle, WA) T2 protein from the Shope fibroma virus [WO9217583]; and Schering-Plough's (Union, NJ) anti-IL-10 [WO9302693]. Also in clinical trials are bradykinin antagonists from Cortech (Denver, CO)

Peter E. Highfield is science and technology manager, Murex Diagnostics, Central Road, Dartford DA1 SLR, U.K.
[WO9217201]; platelet activating factor inhibitors from American Cyanamid (Wayne, NJ) [EP-530444-A] and British Bio-technology (Oxford, U.K.) [WO9203422]; immunostimulants from Biokine (Cirencester, U.K.) [WO9310148], Ribi ImmunoChem (Hamilton, MT) [US4844894], and Alpha-Beta Technology (Worcester, MA) [WO9103248]; and an antiadhesion monoclonal from Cytel (San Diego, CA) [WO9212729].

Much of the recent publicity about sepsis therapies has centered on the problems these early products have had in phase III clinical trials. In some trials, there has been evidence of higher mortality among patients on therapy than on placebo. This is not really surprising: The complex interrelationships between the components involved in infection and death probably militate against a single therapy being effective.

In turn, the ownership of intellectual property relevant to sepsis appears to militate against a more integrated approach to the development of therapies. The patent literature indicates that most companies are following a single line of attack - that for which they own the patent. Rarely do companies have filings in two different areas (although Synergen and Immunex both have IL-1 and TNF inhibitors).

Interestingly, Schering Corp (Berlin, Germany) claims that IL-6 in combination with anti-TNF is a more effective therapy than antibody alone [WO9311793]. If a combined regimen is required for effective sepsis therapy, then owning a sliver of sepsis will not be enough. It seems unlikely with the present distribution of intellectual property that any one company will be able to claim sufficient ownership to build a dominant position. However, if biotechnology companies continue to throw large sums of money at largescale, single-compound clinical trials for sepsis, then perhaps enough of them will go out of business to enable an astute corporate scavenger to acquire enough intellectual property to assemble a more strategic approach to the condition.

\section{Acknowledgment}

The information upon which this article is based came from Expert Opinion on Therapeutic Patents, Ashley Publications, Ist Floor, The Library, 1 Shepherds Hill, Highgate, London N6 5QJ, U.K. Tel: 4481 348 5030. Fax: 44813475040.

\section{References}

1. Choo, Q.L., et al. 1991. Genetic organization and diversity of the hepatitis C virus. Proc. Natl Acad. Sci. U.S.A. 88:2451-5.

2. Bates, P.C., Ledger, P.W., and Aston, R. 1994. Expert Opinion on Therapeutic Patents 4: no.8. 